\title{
BEE POLLEN: ITS ANTIOXIDANT ACTIVITY
}

\author{
Arı Poleni: Antioksidan Etkisi
}

\section{Hidayet TUTUN ${ }^{1}$, Muhammet Mükerrem KAYA ${ }^{1 *}$, Melike Sultan USLUER ${ }^{1}$, Hatice Ahu KAHRAMAN²}

\begin{abstract}
${ }^{1 *}$ Burdur Mehmet Akif Ersoy University, Faculty of Veterinary Medicine, Department of Pharmacology and Toxicology Burdur, TURKEY, ORCID No.: 0000-0001-9512-8637, E-posta: hidayettutun@gmail.com, ORCID No.: 0000-0002-7781-

5342, Yazışma Yazarı / Corresponding Author: : muhammetmukerremkaya@gmail.com., ORCID No.: 0000-0002-93912839, E-posta: melikeusluer.15@gmail.com.

${ }^{2}$ Burdur Mehmet Akif Ersoy University, Faculty of Veterinary Medicine, Department of Food Hygiene and Technology Burdur, TURKEY, ORCID No.: 0000-0001-6600-239X, E-posta: h.ahukahraman@gmail.com
\end{abstract}

Geliş Tarihi / Received: 13.03.2021 Kabul Tarihi / Accepted: 05.04.2021

DOI: 10.31467/uluaricilik. 896045

\begin{abstract}
Bee pollen is a honey bee product containing over 250 biologically active substances such as phenolic bases, amino acids, carbohydrates, lipids, enzymes and coenzymes, vitamins and bio-elements. The composition of bee pollen may vary due to plant sources and its botanical and geographical origin. Bee pollen has been used since ancient times in traditional medicine for its therapeutic effects such as wound healing and hepatoprotective. Bee pollen has been reported to possess antioxidant and radical scavenging activities usually attributed to the presence of phenolic acids and flavonoids which are plant-derived polyphenolic substances. The antioxidant capacity of bee pollen depends on the content of total polyphenolic substances. This review presents an overview of chemical composition and antioxidant activity of bee pollen.
\end{abstract}

Keywords: Antioxidant activity, Bee pollen, Oxidative stress

\section{ÖZET}

Arı poleni fenolik bazlar, amino asitler, karbonhidratlar, lipitler, enzimler ve koenzimler, vitaminler ve biyo-elementler gibi 250 'den fazla biyolojik olarak aktif madde içeren bir arı ürünüdür. Polen bileşimi polenin bitkisel kaynağına, botanik ve coğrafi kökenine göre değişebilir. Arı poleni, yara iyileştirici ve karaciğer koruyucu gibi etkileri nedeniyle geleneksel tıpta eski çağlardan beri kullanılmaktadır. Arı poleninin, genellikle bitkilerden elde edilen polifenolik maddeler olan fenolik asitlerin ve flavonoidlerin varlığına atfedilen antioksidan ve radikal temizleme aktivitelerine sahip olduğu bildirilmiştir. Antioksidan kapasitesi, toplam polifenolik maddelerin içeriğine bağlıdır. Bu derleme arı poleninin kimyasal bileşimi ve antioksidan aktivitesine genel bir bakış sunmaktadır.

Anahtar Kelimeler: Antioksidan aktivite, Arı poleni, Oksidatif stres

\section{GENIŞLETILMIŞ ÖZET}

Amaç: Bal, arı sütü, propolis ve polen gibi arı ürünleri sağlık üzerine yararlı olduğu bilinen birçok biyoaktif maddeyi yapılarında bulundurmaktadırlar. Özellikle flavonoidler, karotenoidler ve fenolik bileşikler gibi maddeler sebebiyle antioksidan aktivite gösterdiği bildirilmiştir. Arı ürünleri içerisinde arı poleni, sahip olduğu biyoaktif bileşiklerin güçlü antioksidan etkilerinin yanı sıra pek çok terapötik etkilere de sahiptir. Bu derlemede arı poleninin özellikleri ve antioksidan etkili bileşiklerinden bahsedilecektir. 
Tartışma: Arı poleni, nektar, çiçek poleni ve arı salgısının bir karışımıdır. Yapılan çalışmalarla ön plana çıkan bu doğal arı ürünü, gıda takviyesi ve potansiyel bir terapötik olarak kabul görmektedir. Arı poleninin yapısı ve kimyasal bileşimi coğrafi bölgeye, ekolojik yapıya ve mevsime bağlı olarak değişiklik gösterebilir. Bunun yanında, arı poleninin işleme süreçleri, saklanma süresi ve koşulları da arı poleninin kimyasal içeriğini etkilemektedir. Bu faktörlere bağlı olarak değişen içerik, arı poleninin antioksidan etkisini değiştirmektedir. Ayrıca, arı poleni ekstraktlarının antioksidan etkileri kullanılan solüsyona göre değişmektedir. En güçlü antioksidan etkiyi etanol ekstraksiyonunda göstermiştir. Arı poleninin antioksidan kapasitesinin ölçümünde $\mathrm{DPPH}, \mathrm{ABTS}^{+}, \mathrm{FRAP}, \mathrm{ORAC}$ gibi birçok yöntem kullanmakta birlikte, tek bir metodun uygulanması gerçek aktiviteyi göstermeye yetmemektedir. Antioksidan kapasitesinin belirlenmesinde reaksiyon mekanizması, izolasyon prosedürleri, biyoaktif bileşenlerin saflığı ve kullanılan substrat gibi çeşitli parametreler dikkate alınmalıdır.

Süperoksit radikalleri $\left(\mathrm{O}_{2}{ }^{\circ}\right)$, hidrojen peroksit $\left(\mathrm{H}_{2} \mathrm{O}_{2}\right)$, hidroksil radikalleri $(\cdot \mathrm{OH})$ ve singlet oksijen $\left({ }^{1} \mathrm{O}_{2}\right)$ genel olarak tanımlanan reaktif oksijen türleri (ROS) olup biyolojik sistemler tarafından metabolik yan ürünler olarak üretilirler. Canlı organizmalar, genellikle ROS'un zararlı etkilerini bloke etmede etkili olan enzimatik ve enzimatik olmayan antioksidanları içeren antioksidan sistemlere sahiptir. Ancak, patolojik durumlarda antioksidan sistemler yetersiz kalabilir. Serbest radikaller ve oksidantlar fazla miktarda üretildiklerinde, oksidatif stres olarak bilinen bir fenomeni ortaya çıkarırlar; bu, zarlar, lipitler, proteinler, lipoproteinler ve deoksiribonükleik asit (DNA) gibi çeşitli hücresel yapıları olumsuz etkileyebilecek zararlı bir süreçtir.

Arı polenlerinin antioksidan aktiviteleri esas olarak $p$ kumarik asit, ferulik asit, gallik asit, klorojenik asit, vanilik asit ve kafeik asit gibi fenolik asitlere, epikateşin, rutin, kuersetin, luteolin, apigenin ve kristin gibi flavonoidlere, resveratrol gibi fitoaleksin ve $E$ ve $C$ vitamini gibi vitaminlere atfedilir. $B u$ biyoaktif maddeler elektofilleri etkisiz hale getirerek, serbest radikalleri ve reaktif oksijen türlerin temizleyerek antioksidan aktivite gösterirler. Ayrıca metal iyonlarını bağlayarak toksik metallerin uzaklaştırılmasını sağlarlar.

Sonuç: Arı poleni gıda takviyesi ve farmasötik ürün geliştirmek için kullanılan en önemli doğal ürünlerden biridir. Yapılan çok sayıda çalışma, oksidasyonun zararlı etkilerine karşı koyabilen doğal bir ajan olarak arı poleninin büyük potansiyelini doğrular niteliktedir. Gıda endüstrisi, bileşiminde bulunan antioksidan bileşikler nedeniyle son yıllarda arı polenine büyük önem vermiştir. Arı poleni, zengin biyoaktif bileşikleri nedeniyle birçok gıda takviyesi ve farmasötik ürünün geliştirilmesi için önemli bir aday olabilir.

\section{INTRODUCTION}

Bee pollen produced by worker honey bees is composed of proteins, sugar, fibre, mineral salts, phenolic compounds and vitamins and used as a food source for all stages of the development of the bees (Campos et al. 2008). It contains known essential nutrients required for the body to make health maintenance and possess a wide range of therapeutic effects including antioxidant, antiinflammatory, anticarcinogenic, antifungal, hepatoprotective, wound healing and immuneregulating (Denisow and Denisow-Pietrzyk 2016, Guiné 2015, LeBlanc et al. 2009, Olczyk et al. 2016, Thakur and Nanda 2020). Oxidative stress is imbalance between free radical-generating and radical scavenging systems in the body, which may contribute to many disorders including cancer, atherosclerosis, cerebral and cardiac ischemia, Parkinson's disease, gastrointestinal disturbances, and aging (Rao et al. 2011). An excess of free radicals formed by oxidative stress attacks vital cellular components including coenzymes, neurotransmitters and macromolecules such as nucleic acids, proteins, lipids and carbohydrates. The cellular radical scavenging system, consisting of antioxidant enzymes, neutralizes the free radicals and prevents free radical damage. However, the living cell has limited capacity on neutralizing the oxidative free radicals formed (Campos et al. 2003). The deficit can be compensated by exogenous antioxidants obtained from the diet and they can increase protection of the body. Additionally, the endogenous antioxidant system performs its functions with exogenous antioxidant systems in a synergistic way (Warraich et al. 2020). Bee pollen has been reported to exhibit antioxidant and radical scavenging activities. Its antioxidant ability has usually been attributed to the presence of phenolic acids and flavonoids (LeBlanc et al. 2009, Leja et al. 2007, Šarić et al. 2009). The composition of bee pollen may vary depending on the species composition of the pollen, catchment areas, weather 
conditions, seasons, and actions of the beekeeper (Campos et al. 2008, Guiné 2015). Thus, the antioxidant activities may vary due to the differences in active ingredients of bee pollen. This chapter will focus on chemical composition and antioxidant activity of bee pollen.

\section{Oxidative stress}

Oxidative stress has been defined as an imbalance between production and accumulation of reactive oxygen species (ROS) due to the disturbance of balance between their production and removal by antioxidant enzymes in cells and tissues (Pizzino et al. 2017). ROS are generated via several oxidative processes, including aerobic metabolism, arachidonic acid metabolism and the activity of NADPH oxidases and xanthine oxidases, during both physiological and pathological conditions (Cho et al. 2011, Pizzino et al. 2017). ROS include free radicals such as superoxide radicals $\left(\mathrm{O}_{2} \cdot-\right)$, hydroxyl radicals $(\cdot \mathrm{OH})$ and nonradical molecules such as hydrogen peroxide $\left(\mathrm{H}_{2} \mathrm{O}_{2}\right)$ and singlet oxygen $\left({ }^{1} \mathrm{O}_{2}\right)$ (Sharma et al. 2012). Oxidative stress occurs as a result of the deterioration in biological systems' ability to detoxify these reactive products (Pizzino et al. 2017). Free radicals are molecules with unpaired electrons and having an odd number of electrons make them unstable, short lived and highly reactive. Due to their high reactivity, free radicals can capture electrons from other compounds to gain stability. Thus, the affected molecule loses its electrons and becomes a free radical itself. The free radical molecules formed initiate the reactions that damage living cells (Phaniendra et al. 2015). Excessive ROS can damage cellular proteins, lipids and DNA, leading to cell death. Mitochondria have their own DNA (called mitochondrial DNA) and their own machinery for synthesizing RNA and proteins. Mitochondrial DNA is considered to be susceptible to ROS attack resulting from oxidative stress. As a result of mitochondrial DNA damage, mutations occur in the mitochondrial genomes, which leads to the development of diseases and an increase in the severity of the diseases (Guo et al. 2013).

\section{Antioxidants}

Antioxidant is used to define the molecules that donate an electron to a rampaging free radical to stabilize it, thus preventing oxidative damage (Lobo et al. 2010). Antioxidants combat free radicals in various ways, including by sequestering metal ions that are the source of free radicals, by suppressing the production of active species, by scavenging and quenching of ROS, by terminating the chain reaction, and by repairing radical's damages of the cell (Rao et al. 2011, Aguilar et al. 2016). Based on their activity, antioxidant defence mechanisms are classified into two types, enzymatic and nonenzymatic. They can be also classified according to their source including endogenous antioxidants that are produced in the body and exogenous antioxidants that are supplied with the diet (Masella et al. 2005, He et al. 2017). Endogenous antioxidant system includes enzymatic antioxidants such as superoxide dismutase (SOD), catalase (CAT), glutathione peroxidase (GTPx), thioredoxin reductase, peroxiredoxin, glutathione-S-transferase (GST) and glutathione reductase (GTRx), and nonenzymatic antioxidants such as albumin, bilirubin, glutathione, uric acid, melatonin, polyamines, and metal binding proteins (ceruloplasmin, transferrin) (Aguilar et al. 2016, Birben et al. 2012, KucielLewandowska et al. 2020, Masella et al. 2005, Rao et al. 2011).

Exogenous antioxidants can be obtained from the diet; however, these antioxidants may not be sufficient to maintain optimal body function. Even though it is best to get the antioxidants from a diet rich in fruits and vegetables, taking antioxidant supplements has become an increasingly popular practice (Pham-Huy et al. 2008). Intake of exogenous antioxidants can play an important role in supporting endogenous antioxidants by combating oxidative stress and increasing protection of the body (Romero et al. 2013). Exogenous antioxidant systems include nonenzymatic antioxidants such as vitamin C (Ascorbic acid), vitamin A ( $\beta$-carotene), vitamin $\mathrm{E}$ ( $\alpha$-tocopherol), Lycopene (Carotenoid), trace elements (Selenium, zinc, manganese), flavonoids and other compounds (Hydroxycinnamic acids, allicin, curcumin) (Rao et al. 2011, Romero et al. 2013).

\section{Antioxidant activity of bee pollen}

Bee pollen, a honey bee derivative product, is used for its nutritious and physiological properties and beneficial effects on human health. It contains many components which are important in the healthy and normal development of the organism, therefore it can be used as a food supplement. Bee pollens have rich phenolic compounds, flavonoids, phytosterols and other chemicals including vitamins and minerals with health protective potential (Denisow and Denisow-Pietrzyk 2016). Numerous studies have demonstrated that bee pollen has potential bioactive 
and therapeutic properties due to its healthy ingredients and these ingredients varies widely according to its botanical and geographical origin hence its therapeutic effects also vary (Oliveira et al. 2019, Adaškevičiūtè et al. 2019, KomosinskaVassev et al. 2015).

Bee pollen has been considered to be a potential natural source of antioxidants due to high antioxidant properties of its active ingredients, especially phenolic compounds. These antioxidant ingredients comprise two main groups of compounds, phenolic compounds (flavonoids and phenolic acids) and carotenoids. Phenolic compounds prevent oxidative stress-mediated DNA and tissue damage from a variety of endogenous and exogenous factors. Flavonoids having subgroups including flavanonols, flavanols (catechins), anthocyanins, chalones, isoflavones and neoflavanoids play a variety of biological activities in plants, animals and bacteria. Flavonoids are secondary metabolites contributing to the colourful pigments of plants and have important roles in the growth, development and defence of plants (Kocot et al. 2018, Panche et al. 2016). They can have effects on antioxidant activity, gene expression, cell signalling or drug metabolizing enzymes and have a phytoestrogenic potential, and show a protective effect against the toxicity of environmental pollutant dioxin (Aličić et al. 2014). The antioxidant activities of flavonoid compounds are related to a group of natural compounds with variable phenolic structures (Cornara et al. 2017, Kocot et al. 2018, Karkar et al. 2020). Flavonoids act as antioxidants by direct elimination of the radicals, interaction with enzymes or chelatically binding the metal cations. Phenolic compounds also enable free radicals to be neutralized mainly by quenching oxygen or decomposing peroxides. Bee pollen also contains carotenoids that have antioxidant activity. Carotenoids are naturally occurring pigments responsible for yellow, orange, and red in plants, algae and photosynthetic bacteria and can scavenge the radicals with different ways such as electron transfer, addition reactions and elimination of hydrogen (Aličić et al. 2014, Fatrcová-Šramková et al. 2016).

Bee pollen has been reported to exert free radicalscavenging activity and inhibitory effect on lipid peroxidation. Antioxidant ability of bee pollen has been attributed to its contents with antioxidant properties/activities (Leja et al. 2007). The measure of its antioxidant activities has been expressed by antioxidant capacity. Many factors may be important in accurately defining antioxidant activity. Many assays used to determine the antioxidant capacity of bee pollen are based on different mechanisms of antioxidant defence systems such as the removal or inhibition of free radicals or chelation of metal ions (Aličić et al. 2014). It has been reported that antioxidant activity of bee pollen may vary depending on its content. Therefore, different findings have been obtained in studies with bee pollen samples collected from different areas (Kocot et al. 2018, Leja et al. 2007, Saral et al. 2019).

Various methods including direct and indirect assays are available to evaluate the antioxidant capacity of bee pollen. Trolox (6-hydroxy-2,5,7,8tetramethylchroman-2-carboxylic acid) equivalent antioxidant capacity (TEAC) and oxygen radical absorbance capacity (ORAC) assays are the most commonly used direct assays for determining the capacity. The most frequently used indirect methods are 2,2-diphenyl-1-picrylhydrazyl (DPPH•), ABTS (2,2-azino-bis-3-. ethylbenzothiazoline-6-sulfonic acid), ferric reducing ability of plasma (FRAP). These assays provide useful data but are not sufficient to evaluate the overall antioxidant capacity of the content (Aličić et al. 2014, Okan et al. 2013, Mărghitaschedilla et al. 2009, Fatiha and Abdelkader 2019, Pisoschi and Negulescu 2011, Moniruzzaman et al. 2011).

\section{Antioxidant compounds of bee pollen}

Bee pollen has a rich chemical structure such as proteins, free amino acids, carbohydrates, lipids, fatty acids, phenolic compounds, vitamins (including B-complex and folic acid) and minerals. The high content of carbohydrates (13\% to $55 \%$ ), crude fibres $(0.3 \%$ to $20 \%)$, proteins (10\% to $40 \%$ ) and lipids ( $1 \%$ to $10 \%$ ) highlights bee pollen as a good nutritional supplement (Villanueva et al. 2002). Other minor components are minerals, vitamins, carotenoids, phenolic compounds, flavonoids, sterols and terpenes (Feás et al. 2012). Bee pollen contains provitamin $A$ ( $\beta$-carotene) and vitamin $E, D, B 1, B 2$, $B 6$ and $C$, and acids like pantothenic, nicotinic, folic, biotin, rutin and inositol (Komosinska-Vassev et al. 2015).

Honey bees use a variety of flowering plants for bee pollen production. When the bees start foraging to gather pollen, they visit the same species of flowers, and that pollen is mainly monofloral origin with minor additions of other species (Aličić et al. 2014). The composition of bee pollen depends mainly on botanical sources, together with other factors 


\section{DERLEME / REVIEW}

including soil type, climatic conditions and anthropogenic activities (Pascoal et al. 2014), thus strongly affecting antioxidant properties. A high number of in vitro studies using DPPH, $\mathrm{ABTS}^{+}$, FRAP, ORAC methods have confirmed the antioxidant potentials of bee pollens (Šarić et al. 2009, Ulusoy and Kolayli 2014, Kaškonienè et al. 2015, Mohdaly et al. 2015, Kocot et al. 2018, Özcan et al. 2019). The antioxidant activities of the bee pollens seem to be mainly due to phenolic acids like $p$-coumaric acid, ferulic acid, gallic acid, chlorogenic acid, vanillic acid, caffeic acid and syringic acid, flavonoids like epicatechin, rutin, quercetin, luteolin, apigenin, kaempferol, pinocembrin and chrysin, phytoalexin like resveratrol and vitamins like vitamin $\mathrm{E}$ and $\mathrm{C}$. Compounds with antioxidant activity in bee pollen are given in Table 1. Antioxidant capacity of bee pollen and methods used to determine antioxidant capacity are given in Table 2 .

Table 1. Compounds with antioxidant properties in honey bee pollens.

\begin{tabular}{|c|c|c|c|}
\hline Compounds & Pollen origin & Range & Reference \\
\hline \multirow[t]{5}{*}{$p$-coumaric acid } & Egypt & $2.48 \pm 0.25 \mathrm{mg} / \mathrm{mL}$ & Mohdaly et al. 2015 \\
\hline & Brazil & $0.24 \pm 0.02 \mathrm{mg} / \mathrm{g}$ & de Florio Almeida et al. 2017 \\
\hline & Anzer pollen from Turkey & $34.16-127.85 \mu \mathrm{g} / 100 \mathrm{~g}$ & Ulusoy and Kolayli 2014 \\
\hline & $\begin{array}{l}\text { Bee pollen from Turkey and } \\
\text { Russia }\end{array}$ & $\begin{array}{l}1.39 \pm 0.10-10.46 \pm 0.18 \\
\mathrm{mg} / 100 \mathrm{~g}\end{array}$ & Özcan et al. 2019 \\
\hline & Rape bee pollen from China & $\begin{array}{l}32.63 \pm 2.19 \mu \mathrm{g} / \mathrm{g} \text { FPE } \\
11.22 \pm 0.10 \mu \mathrm{g} / \mathrm{g} \mathrm{BPE}\end{array}$ & Sun et al. 2017 \\
\hline \multirow[t]{4}{*}{ Gallic acid } & Anzer pollen from Turkey & $9.15-18.59 \mu \mathrm{g} / 100 \mathrm{~g}$ & Ulusoy and Kolayli 2014 \\
\hline & Bee pollen from Egypt & $5.9 \pm 0.05 \mathrm{mg} / \mathrm{mL}$ & Mohdaly et al. 2015 \\
\hline & $\begin{array}{l}\text { Bee pollen from Latvia, } \\
\text { Lithuania, Spain and China }\end{array}$ & $3.0-32.3 \mu \mathrm{g} / \mathrm{g}$ & Kaškonienè et al. 2015 \\
\hline & $\begin{array}{l}\text { Bee pollen from Turkey and } \\
\text { Russia }\end{array}$ & $\begin{array}{l}6.17 \pm 0.08-32.89 \pm 0.62 \\
\mathrm{mg} / 100 \mathrm{~g}\end{array}$ & Özcan et al. 2019 \\
\hline \multirow{3}{*}{$\begin{array}{l}\text { Protocatechuic acid } \\
(3,4- \\
\text { dihydroxybenzoic } \\
\text { acid) }\end{array}$} & Anzer pollen from Turkey & $8.31-19.77 \mu \mathrm{g} / 100 \mathrm{~g}$ & Ulusoy and Kolayli 2014 \\
\hline & Rape bee pollen from China & $119.38 \pm 4.82 \mu \mathrm{g} / \mathrm{g}$ FPE & Sun et al. 2017 \\
\hline & $\begin{array}{l}\text { Bee pollen from Turkey and } \\
\text { Russia }\end{array}$ & $\begin{array}{l}17.09 \pm 0.56-94.74 \pm 2.99 \\
\mathrm{mg} / 100 \mathrm{~g}\end{array}$ & Özcan et al. 2019 \\
\hline \multirow[t]{2}{*}{ p-OH benzoic acid } & Anzer pollen from Turkey & $2.74-122.68 \mu \mathrm{g} / 100 \mathrm{~g}$ & Ulusoy and Kolayli 2014 \\
\hline & Rape bee pollen from China & $\begin{array}{l}84.28 \pm 5.29 \mu \mathrm{g} / \mathrm{g} \text { FPE } \\
11.08 \pm 0.13 \mu \mathrm{g} / \mathrm{g} \text { BPE }\end{array}$ & Sun et al. 2017 \\
\hline Abscisic acid & Anzer pollen from Turkey & $21.04-288.70 \mu \mathrm{g} / 100 \mathrm{~g}$ & Ulusoy and Kolayli 2014 \\
\hline \multirow[t]{2}{*}{ Benzoic acid } & Anzer pollen from Turkey & $46.87-1,077.64 \mu \mathrm{g} / 100 \mathrm{~g}$ & Ulusoy and Kolayli 2014 \\
\hline & Rape bee pollen from China & $\begin{array}{l}314.16 \pm 11.87 \mu \mathrm{g} / \mathrm{g} \text { FPE } \\
3.46 \pm 0.14 \mu \mathrm{g} / \mathrm{g} \text { BPE }\end{array}$ & Sun et al. 2017 \\
\hline $\begin{array}{l}\text { 1,2- } \\
\text { dihydroxybenzene }\end{array}$ & $\begin{array}{l}\text { Bee pollen from Turkey and } \\
\text { Russia }\end{array}$ & $\begin{array}{l}8.34 \pm 0.48-114.97 \pm 0.03 \\
\mathrm{mg} / 100 \mathrm{~g}\end{array}$ & Özcan et al. 2019 \\
\hline $\begin{array}{l}\text { Apigenin-7- } \\
\text { glucoside }\end{array}$ & $\begin{array}{l}\text { Bee pollen from Turkey and } \\
\text { Russia }\end{array}$ & $\begin{array}{l}4.24 \pm 0.17-24.31 \pm 0.41 \\
\mathrm{mg} / 100 \mathrm{~g}\end{array}$ & Özcan et al. 2019 \\
\hline Chlorogenic acid & Anzer pollen from Turkey & $14.64-75.08 \mu \mathrm{g} / 100 \mathrm{~g}$ & Ulusoy and Kolayli 2014 \\
\hline $\begin{array}{l}\text { Chlorogenic acid/ } \\
\text { Caffeic acid }\end{array}$ & Bee pollen from Central Chile & $\begin{array}{l}11.29 \pm 0.45-258.92 \pm 10.36 \\
\mathrm{mg} / \mathrm{kg}\end{array}$ & Velasquez et al. 2017 \\
\hline \multirow{2}{*}{$\begin{array}{l}\text { Trans-cinnamic } \\
\text { acid }\end{array}$} & Bee pollen from Brazil & $0.27 \pm 0.01 \mathrm{mg} / \mathrm{g}$ & de Florio Almeida et al. 2017 \\
\hline & Rape bee pollen from China & $\begin{array}{l}102.65 \pm 3.79 \mu \mathrm{g} / \mathrm{g} \mathrm{FPE} \\
2.30 \pm 0.17 \mu \mathrm{g} / \mathrm{g} \mathrm{BPE}\end{array}$ & Sun et al. 2017 \\
\hline \multirow[t]{2}{*}{ Vanillic acid } & Anzer pollen from Turkey & $22.96-87.02 \mu \mathrm{g} / 100 \mathrm{~g}$ & Ulusoy and Kolayli 2014 \\
\hline & Bee pollen from Egypt & $0.35 \pm 0.15 \mathrm{mg} / \mathrm{mL}$ & Mohdaly et al. 2015 \\
\hline Vanillin & Rape bee pollen from China & $58.41 \pm 1.22 \mu \mathrm{g} / \mathrm{g}$ FPE & Sun et al. 2017 \\
\hline \multirow[t]{4}{*}{ Caffeic acid } & Anzer pollen from Turkey & $10.88-98.03 \mu \mathrm{g} / 100 \mathrm{~g}$ & Ulusoy and Kolayli 2014 \\
\hline & Bee pollen from Egypt & $4.21 \pm 0.22 \mathrm{mg} / \mathrm{mL}$ & Mohdaly et al. 2015 \\
\hline & $\begin{array}{l}\text { Bee pollen from Latvia, } \\
\text { Lithuania, Spain and China }\end{array}$ & $8.5-20.6 \mu \mathrm{g} / \mathrm{g}$ & Kaškonienè et al. 2015 \\
\hline & $\begin{array}{l}\text { Bee pollen from Turkey and } \\
\text { Russia }\end{array}$ & $\begin{array}{l}5.84 \pm 0.35-23.86 \pm 0.63 \\
\mathrm{mg} / 100 \mathrm{~g}\end{array}$ & Özcan et al. 2019 \\
\hline Syringic acid & Anzer pollen from Turkey & $10.55-259.53 \mu \mathrm{g} / 100 \mathrm{~g}$ & Ulusoy and Kolayli 2014 \\
\hline
\end{tabular}


DERLEME / REVIEW

\begin{tabular}{|c|c|c|c|}
\hline Compounds & Pollen origin & Range & Reference \\
\hline & Bee pollen from Egypt & $0.59 \pm 0.08 \mathrm{mg} / \mathrm{mL}$ & Mohdaly et al. 2015 \\
\hline & $\begin{array}{l}\text { Bee pollen from Turkey and } \\
\text { Russia }\end{array}$ & $\begin{array}{l}5.56 \pm 0.01-23.77 \pm 0.01 \\
\mathrm{mg} / 100 \mathrm{~g}\end{array}$ & Özcan et al. 2019 \\
\hline Sinapic acid & Bee pollen from Central Chile & $\begin{array}{l}9.12 \pm 0.36-89.67 \pm 3.59 \\
\mathrm{mg} / \mathrm{kg}\end{array}$ & Velasquez et al. 2017 \\
\hline \multirow[t]{5}{*}{ Ferulic acid } & Anzer pollen from Turkey & $36.83-230.55 \mu \mathrm{g} / 100 \mathrm{~g}$ & Ulusoy and Kolayli 2014 \\
\hline & Bee pollen from Egypt & $4.2 \pm 0.18 \mathrm{mg} / \mathrm{mL}$ & Mohdaly et al. 2015 \\
\hline & $\begin{array}{l}\text { Bee pollen from Latvia, } \\
\text { Lithuania, Spain and China }\end{array}$ & $14.6-68.6 \mu \mathrm{g} / \mathrm{g}$ & Kaškonienè et al. 2015 \\
\hline & Bee pollen from Central Chile & $\begin{array}{l}5.48 \pm 0.22-26.33 \pm 1.05 \\
\mathrm{mg} / \mathrm{kg}\end{array}$ & Velasquez et al. 2017 \\
\hline & Bee pollen from Brazil & $0.01 \pm 0.01 \mathrm{mg} / \mathrm{g}$ & de Florio Almeida et al. 2017 \\
\hline \multirow{3}{*}{$\begin{array}{l}\text { o-coumaric acid } \\
(2- \\
\text { Hydroxycinnamic } \\
\text { acid) }\end{array}$} & Anzer pollen from Turkey & $2.63-42.23 \mu \mathrm{g} / 100 \mathrm{~g}$ & Ulusoy and Kolayli 2014 \\
\hline & $\begin{array}{l}\text { Bee pollen from Latvia, } \\
\text { Lithuania, Spain and China }\end{array}$ & $43.4-179.9 \mu \mathrm{g} / \mathrm{g}$ & Kaškonienė et al. 2015 \\
\hline & Bee pollen from Central Chile & $\begin{array}{l}4.02 \pm 0.16-630.92 \pm 25.24 \\
\mathrm{mg} / \mathrm{kg}\end{array}$ & Velasquez et al. 2017 \\
\hline \multirow[t]{3}{*}{ Tert-cinnamic acid } & Anzer pollen from Turkey & $6.82-56.38 \mu \mathrm{g} / 100 \mathrm{~g}$ & Ulusoy and Kolayli 2014 \\
\hline & $\begin{array}{l}\text { Bee pollen from Turkey and } \\
\text { Russia }\end{array}$ & $\begin{array}{l}1.57 \pm 0.18-181.33 \pm 0.25 \\
\mathrm{mg} / 100 \mathrm{~g}\end{array}$ & Özcan et al. 2019 \\
\hline & Bee pollen from Central Chile & $6.49 \pm 0.26-8.93 \pm 0.36 \mathrm{mg} / \mathrm{kg}$ & Velasquez et al. 2017 \\
\hline \multirow[t]{6}{*}{ Rutin } & Anzer pollen from Turkey & $25.59-692.85 \mu \mathrm{g} / 100 \mathrm{~g}$ & Ulusoy and Kolayli 2014 \\
\hline & Bee pollen from Egypt & $3.46 \pm 0.14 \mathrm{mg} / \mathrm{mL}$ & Mohdaly et al. 2015 \\
\hline & $\begin{array}{l}\text { Bee pollen from Latvia, } \\
\text { Lithuania, Spain and China }\end{array}$ & $156.2-955.7 \mu \mathrm{g} / \mathrm{g}$ & Kaškonienė et al. 2015 \\
\hline & $\begin{array}{l}\text { Bee pollen from Turkey and } \\
\text { Russia }\end{array}$ & $\begin{array}{l}9.82 \pm 0.62-80.47 \pm 0.46 \\
\mathrm{mg} / 100 \mathrm{~g}\end{array}$ & Özcan et al. 2019 \\
\hline & Rape bee pollen from China & $\begin{array}{l}774.87 \pm 8.77 \mu \mathrm{g} / \mathrm{g} \mathrm{FPE} \\
6.45 \pm 0.40 \mu \mathrm{g} / \mathrm{g} \mathrm{BPE}\end{array}$ & Sun et al. 2017 \\
\hline & Bee pollen from Brazil & $0.02 \pm 0.01 \mathrm{mg} / \mathrm{g}$ & de Florio Almeida et al. 2017 \\
\hline \multirow[t]{8}{*}{ Quercetin } & $\begin{array}{l}\text { Sunflower bee pollen from } \\
\text { Western Slovakia }\end{array}$ & $10.19-14.30 \mathrm{mg} / \mathrm{kg}$ & $\begin{array}{l}\text { Fatrcová-Šramková et al. } \\
2016\end{array}$ \\
\hline & $\begin{array}{l}\text { Cystus incanus L. rich bee } \\
\text { pollen from Croatia }\end{array}$ & $\begin{array}{l}3.25 \mu \mathrm{mol} / \mathrm{g} \text { (hydrolyzed } \\
\text { extracts) }\end{array}$ & Šarić et al. 2009 \\
\hline & Anzer pollens from Turkey & $55.94-499.20 \mu \mathrm{g} / 100 \mathrm{~g}$ & Ulusoy and Kolayli 2014 \\
\hline & Bee pollen from Egypt & $6.4 \pm 0.30 \mathrm{mg} / \mathrm{mL}$ & Mohdaly et al. 2015 \\
\hline & $\begin{array}{l}\text { Bee pollen from Latvia, } \\
\text { Lithuania, Spain and China }\end{array}$ & $24.0-529.8 \mu \mathrm{g} / \mathrm{g}$ & Kaškonienė et al. 2015 \\
\hline & Rape bee pollen from China & $196.38 \pm 3.14 \mu \mathrm{g} / \mathrm{g}$ FPE & Sun et al.2017 \\
\hline & $\begin{array}{l}\text { Bee pollen from Turkey and } \\
\text { Russia }\end{array}$ & $\begin{array}{l}61.23 \pm 0.76-685.36 \pm 0.60 \\
\mathrm{mg} / 100 \mathrm{~g}\end{array}$ & Özcan et al. 2019 \\
\hline & Bee pollen from Brazil & $0.32 \pm 0.02 \mathrm{mg} / \mathrm{g}$ & de Florio Almeida et al. 2017 \\
\hline Luteolin & $\begin{array}{l}\text { Sunflower bee pollen from } \\
\text { Western Slovakia }\end{array}$ & $46.96-66.39 \mathrm{mg} / \mathrm{kg}$ & $\begin{array}{l}\text { Fatrcová-Šramková et al. } \\
2016\end{array}$ \\
\hline \multirow[t]{2}{*}{ Apigenin } & $\begin{array}{l}\text { Sunflower bee pollen from } \\
\text { Western Slovakia }\end{array}$ & $23.99-34.40 \mathrm{mg} / \mathrm{kg}$ & $\begin{array}{lll}\begin{array}{l}\text { Fatrcová-Šramková } \\
2016\end{array} & \text { et al. } \\
\end{array}$ \\
\hline & Bee pollen from Egypt & $2.4 \pm 0.25 \mathrm{mg} / \mathrm{mL}$ & Mohdaly et al. 2015 \\
\hline \multirow[t]{6}{*}{ Kaempferol } & Bee pollen from Egypt & $1.65 \pm 0.24 \mathrm{mg} / \mathrm{mL}$ & Mohdaly et al. 2015 \\
\hline & $\begin{array}{l}\text { Cystus incanus L. rich bee } \\
\text { pollen from Croatia }\end{array}$ & $1.563 \mu \mathrm{mol} / \mathrm{g}$ & Šarić et al. 2009 \\
\hline & $\begin{array}{l}\text { Bee pollen from Turkey and } \\
\text { Russia }\end{array}$ & $\begin{array}{l}1.91 \pm 0.10-39.37 \pm 0.14 \\
\mathrm{mg} / 100 \mathrm{~g}\end{array}$ & Özcan et al. 2019 \\
\hline & Bee pollen from Central Chile & $\begin{array}{l}5.33 \pm 0.21-344.20 \pm 13.76 \\
\mathrm{mg} / \mathrm{kg}\end{array}$ & Velasquez et al. 2017 \\
\hline & Rape bee pollen from China & $\begin{array}{l}9.26 \pm 6.21 \mu \mathrm{g} / \mathrm{g} \text { FPE } \\
0.17 \pm 0.18 \mu \mathrm{g} / \mathrm{g} \mathrm{BPE}\end{array}$ & Sun et al. 2017 \\
\hline & Bee pollen from Brazil & $0.68 \pm 0.02 \mathrm{mg} / \mathrm{g}$ & de Florio Almeida et al. 2017 \\
\hline Pinocembrin & $\begin{array}{l}\text { Cystus incanus L. rich bee } \\
\text { pollen from Croatia }\end{array}$ & $\begin{array}{l}1.418 \mu \mathrm{mol} / \mathrm{g} \text { (nonhydrolyzed } \\
\text { extracts) }\end{array}$ & Šarić et al. 2009 \\
\hline
\end{tabular}




\section{DERLEME / REVIEW}

\begin{tabular}{|c|c|c|c|}
\hline Compounds & Pollen origin & Range & Reference \\
\hline Chrysin & $\begin{array}{l}\text { Cystus incanus L. rich bee } \\
\text { pollen from Croatia }\end{array}$ & $\begin{array}{l}1.351 \mu \mathrm{mol} / \mathrm{g} \text { (nonhydrolyzed } \\
\text { extracts) and } 0.786 \mu \mathrm{mol} / \mathrm{g} \\
\text { (hydrolyzed extracts) }\end{array}$ & Šarić et al. 2009 \\
\hline Galangin & $\begin{array}{l}\text { Cystus incanus L. rich bee } \\
\text { pollen from Croatia }\end{array}$ & $\begin{array}{l}0.859 \mu \mathrm{mol} / \mathrm{g} \text { (nonhydrolyzed } \\
\text { extracts) }\end{array}$ & Šarić et al. 2009 \\
\hline Isorhamnetin & $\begin{array}{l}\text { Cystus incanus L. rich bee } \\
\text { pollen from Croatia }\end{array}$ & $\begin{array}{l}6.705 \mu \mathrm{mol} / \mathrm{g} \text { (hydrolyzed } \\
\text { extracts) }\end{array}$ & Šarić et al. 2009 \\
\hline \multirow[t]{2}{*}{ Protocatechuic acid } & Anzer pollen from Turkey & $8.31-19.77 \mu \mathrm{g} / 100 \mathrm{~g}$ & Ulusoy and Kolayli 2014 \\
\hline & Rape bee pollen from China & $119.38 \pm 4.82 \mu \mathrm{g} / \mathrm{g}$ FPE & Sun et al. 2017 \\
\hline Myricetin & Bee pollen from Brazil & $0.04 \pm 0.07 \mathrm{mg} / \mathrm{g}$ & de Florio Almeida et al. 2017 \\
\hline \multirow[t]{2}{*}{ Catechin } & Bee pollen from Egypt & $4.8 \pm 0.18 \mathrm{mg} / \mathrm{mL}$ & Mohdaly et al. 2015 \\
\hline & $\begin{array}{l}\text { Bee pollen from Turkey and } \\
\text { Russia }\end{array}$ & $\begin{array}{l}73.88 \pm 5.35-337.40 \pm 0.87 \\
\mathrm{mg} / 100 \mathrm{~g}\end{array}$ & Özcan et al. 2019 \\
\hline$\alpha$-Catechin & Bee pollen from Egypt & $0.58 \pm 0.05 \mathrm{mg} / \mathrm{mL}$ & Mohdaly et al. 2015 \\
\hline $\begin{array}{l}\text { 3,4-dimethoxy } \\
\text { cinnamic acid }\end{array}$ & Bee pollen from Egypt & $45.8 \pm 0.16 \mathrm{mg} / \mathrm{mL}$ & Mohdaly et al. 2015 \\
\hline \multirow[t]{3}{*}{ Naringenin } & Bee pollen from Egypt & $3.34 \pm 0.12 \mathrm{mg} / \mathrm{mL}$ & Mohdaly et al. 2015 \\
\hline & $\begin{array}{l}\text { Bee pollen from the Baltic } \\
\text { Region }\end{array}$ & $3.1-118.0 \mu \mathrm{g} / \mathrm{g}$ & Kaškonienè et al. 2015 \\
\hline & $\begin{array}{l}\text { Bee pollen from Turkey and } \\
\text { Russia }\end{array}$ & $\begin{array}{l}4.43 \pm 0.21-501.13 \pm 2.38 \\
\mathrm{mg} / 100 \mathrm{~g}\end{array}$ & Özcan et al. 2019 \\
\hline \multirow[t]{2}{*}{ Luteolin } & Bee pollen from Egypt & $2.8 \pm 0.10 \mathrm{mg} / \mathrm{mL}$ & Mohdaly et al. 2015 \\
\hline & Bee pollen from Central Chile & $316.00 \pm 2.64 \mathrm{mg} / \mathrm{kg}$ & Velasquez et al. 2017 \\
\hline \multirow[t]{2}{*}{ Epicatechin } & Anzer pollen from Turkey & $39.15-520.02 \mu \mathrm{g} / 100 \mathrm{~g}$ & Ulusoy and Kolayli 2014 \\
\hline & Bee pollen from Egypt & $2.1 \pm 0.08 \mathrm{mg} / \mathrm{mL}$ & Mohdaly et al. 2015 \\
\hline Isorhamnetin & $\begin{array}{l}\text { Bee pollen from Turkey and } \\
\text { Russia }\end{array}$ & $\begin{array}{l}2.21 \pm 0.08-71.23 \pm 0.40 \\
\mathrm{mg} / 100 \mathrm{~g}\end{array}$ & Özcan et al. 2019 \\
\hline Anthocyanins & Tuscan bee pollen from Italy & $\begin{array}{l}77.37 \pm 2.25-57.19 \pm 5.84 \\
\mathrm{mgC} 3 \mathrm{GE} / \mathrm{L}\end{array}$ & Gabriele et al. 2015 \\
\hline \multirow[t]{2}{*}{ Resveratrol } & $\begin{array}{l}\text { Bee pollen from Turkey and } \\
\text { Russia }\end{array}$ & $\begin{array}{l}3.83 \pm 0.09-82.02 \pm 0.04 \\
\mathrm{mg} / 100 \mathrm{~g}\end{array}$ & Özcan et al. 2019 \\
\hline & Rape bee pollen from China & $\begin{array}{l}242.88 \pm 6.32 \mu \mathrm{g} / \mathrm{g} \text { FPE } \\
4.39 \pm 0.13 \mu \mathrm{g} / \mathrm{g} \mathrm{BPE}\end{array}$ & Sun et al. 2017 \\
\hline Vitamin B1 & $\begin{array}{l}\text { Rose bee pollen from Hubei } \\
\text { Province in China }\end{array}$ & $\begin{array}{l}261.28 \pm 4.09-1043.99 \pm 0.22 \\
\mu \mathrm{g} / \mathrm{g}\end{array}$ & Yang et al. 2019 \\
\hline \multirow[t]{2}{*}{ Vitamin E } & Bee pollen from Brazil & $13.5-42.5 \mu \mathrm{g} / \mathrm{g}$ & Oliveira et al. 2009 \\
\hline & $\begin{array}{l}\text { Multifloral fresh bee pollen from } \\
\text { Turkey }\end{array}$ & $162.35 \pm 5.07 \mu \mathrm{g} / \mathrm{g}$ dry pollen & Kanar and Mazı 2019 \\
\hline \multirow[t]{3}{*}{ Vitamin C } & Bee pollen from Brazil & $273.9-560.3 \mu \mathrm{g} / \mathrm{g}$ & Oliveira et al. 2009 \\
\hline & $\begin{array}{l}\text { Multifloral fresh bee pollen from } \\
\text { Turkey }\end{array}$ & $451.50 \pm 6.36 \mu \mathrm{g} / \mathrm{g}$ dry pollen & Kanar and Mazı 2019 \\
\hline & Rose bee pollen from China & $\begin{array}{l}12.52 \pm 1.38-262.74 \pm 3.30 \\
\mu \mathrm{g} / \mathrm{g}\end{array}$ & Yang et al. 2019 \\
\hline$\beta$-carotene & Bee pollen from Brazil & $56.3-198.9 \mu \mathrm{g} / \mathrm{g}$ & Oliveira et al. 2009 \\
\hline \multirow{4}{*}{$\begin{array}{l}\text { Total carotenoid } \\
\text { content }\end{array}$} & Bee pollen from Central Chile & $2.8-50.2 \mathrm{mg} / \mathrm{kg}$ & Velasquez et al. 2017 \\
\hline & Bee pollen from Brazil & $0.49-242.6 \mu \mathrm{g} / \mathrm{g}$ & Oliveira et al. 2009 \\
\hline & $\begin{array}{l}\text { Bee pollen from Turkey and } \\
\text { Russia }\end{array}$ & $\begin{array}{l}12.78 \pm 0.01-98.62 \pm 0.02 \\
\mathrm{mg} / \mathrm{g}\end{array}$ & Özcan et al. 2019 \\
\hline & $\begin{array}{l}\text { Sunflower bee pollen from } \\
\text { Western Slovakia }\end{array}$ & $\begin{array}{l}223.10 \pm 1.24-261.33 \pm 1.36 \\
\mathrm{mg} / \mathrm{kg}\end{array}$ & $\begin{array}{l}\text { Fatrcová-Šramková et al. } \\
2016\end{array}$ \\
\hline \multirow[t]{4}{*}{$\begin{array}{l}\text { Total flavonoid } \\
\text { content }\end{array}$} & $\begin{array}{l}\text { Sunflower bee pollen from } \\
\text { Western Slovakia }\end{array}$ & $93.40-105.82 \mathrm{mg} / \mathrm{kg}$ & $\begin{array}{l}\text { Fatrcová-Šramková et al. } \\
2016\end{array}$ \\
\hline & $\begin{array}{l}\text { Trigona apicalis bee pollen } \\
\text { Trigona thoracica bee pollen } \\
\text { Trigona itama bee pollen }\end{array}$ & $\begin{array}{l}25.72 \pm 0.17 \mathrm{mg} \mathrm{QE} / \mathrm{g} \\
31.80 \pm 0.13 \mathrm{mg} \mathrm{QE} / \mathrm{g} \\
15.28 \pm 0.04 \mathrm{mg} \mathrm{QE} / \mathrm{g}\end{array}$ & Harif Fadzilah et al. 2017 \\
\hline & $\begin{array}{l}\text { Honeybee pollen from the Baltic } \\
\text { Region }\end{array}$ & $\begin{array}{l}\text { 6.1-11.6 RE }(\mathrm{mg} / \mathrm{g}) \\
2.7-5.2 \text { QE }(\mathrm{mg} / \mathrm{g})\end{array}$ & Kaškonienè et al. 2015 \\
\hline & $\begin{array}{l}\text { Bee pollen from Europe } \\
\text { Countries }\end{array}$ & 10.68-48.31 mg RUE/10 g & Adaškevičiūtė et al. 2019 \\
\hline
\end{tabular}


DERLEME / REVIEW

\begin{tabular}{|c|c|c|c|}
\hline Compounds & Pollen origin & Range & Reference \\
\hline & $\begin{array}{l}\text { Monofloral bee pollen from } \\
\text { Brazil }\end{array}$ & $0.3 \pm 0.0-9.0 \pm 0.6 \mathrm{mg} \mathrm{GAE} / \mathrm{g}$ & De-Melo et al. 2018 \\
\hline & Bee pollen from Brazil & $5.95 \mathrm{mg}$ quercetin/g & Soares de Arruda et al. 2020 \\
\hline & Bee pollen from Greece & $6.0 \pm 0.3-57.6 \pm 2.0 \mathrm{mg} \mathrm{QE} / \mathrm{g}$ & Atsalakis et al. 2017 \\
\hline & Bee pollen from Portugal & 4.5-7.1 GAE/g & Feás et al. 2012 \\
\hline & Rose bee pollen from China & $\begin{array}{l}16.44 \pm 1.20-27.96 \pm 0.03 \\
\mathrm{mg} / \mathrm{g}\end{array}$ & Yang et al. 2019 \\
\hline & Bee pollen from Turkey & $\begin{array}{l}2.62 \pm 0.047-4.44 \pm 0.125 \mathrm{mg} \\
\mathrm{QE} / \mathrm{g}\end{array}$ & Mayda et al. 2020 \\
\hline & Rape bee pollen from China & $\begin{array}{l}19.24 \pm 0.06 \mathrm{mg} \mathrm{RE} / \mathrm{g} \mathrm{FPE} \\
3.65 \pm 0.03 \mathrm{mg} \mathrm{RE} / \mathrm{g} \mathrm{BPE}\end{array}$ & Sun et al. 2017 \\
\hline \multirow{19}{*}{$\begin{array}{l}\text { Total phenolic } \\
\text { content }\end{array}$} & Bee pollen from Istanbul/Turkey. & 147.10-462.02 mg GAE/g & Dulger Altiner et al. 2020 \\
\hline & Trigona apicalis bee pollen & $135.93 \pm 0.02 \mathrm{mg} \mathrm{GAE} / \mathrm{g}$ & \\
\hline & $\begin{array}{l}\text { Trigona thoracica bee pollen } \\
\text { Trigona itama bee pollen }\end{array}$ & $\begin{array}{l}103.62 \pm 0.04 \mathrm{mg} \mathrm{GAE} / \mathrm{g} \\
33.46 \pm 0.02 \mathrm{mg} \mathrm{GAE} / \mathrm{g}\end{array}$ & Harif Fadzilah et al. 2017 \\
\hline & Anzer pollen from Turkey & $44.07-124.10 \mathrm{mg} / \mathrm{g}$ & Ulusoy and Kolayli 2014 \\
\hline & Rape bee pollen from China & $\begin{array}{l}11.76 \pm 0.04 \mathrm{mg} \mathrm{GAE} / \mathrm{g} \text { FPE } \\
0.81 \pm 0.01 \mathrm{mg} \mathrm{GAE} / \mathrm{g} \text { BPE }\end{array}$ & Sun et al. 2017 \\
\hline & $\begin{array}{l}\text { Bee pollen from Latvia, } \\
\text { Lithuania, Spain and China }\end{array}$ & $\begin{array}{l}\text { 24.1-45.5 RE }(\mathrm{mg} / \mathrm{g}) \\
\text { 17.7-26.8 GAE }(\mathrm{mg} / \mathrm{g}) \\
\text { 13.4-25.2 QE }(\mathrm{mg} / \mathrm{g})\end{array}$ & Kaškonienè et al. 2015 \\
\hline & $\begin{array}{l}\text { Bee pollen from Europe } \\
\text { Countries }\end{array}$ & 33.14-55.04 mg RUE/10 g & Adaškevičiūtè et al. 2019 \\
\hline & $\begin{array}{l}\text { Monofloral bee pollen from } \\
\text { Brazil }\end{array}$ & $5.6 \pm 0.0-29.7 \pm 0.3 \mathrm{mg} \mathrm{GAE} / \mathrm{g}$ & De-Melo et al. 2018 \\
\hline & Bee pollen from Brazil & $27.94 \mathrm{mg} \mathrm{GAE} / \mathrm{g}$ & Soares de Arruda et al. 2020 \\
\hline & Bee pollen from Greece & $\begin{array}{l}15.2 \pm 0.4-60.2 \pm 2.0 \mathrm{mg} \\
\mathrm{GAE} / \mathrm{g}\end{array}$ & Atsalakis et al. 2017 \\
\hline & Bee pollen from Portugal & 12.9-19.8 GAE/g & Feás et al. 2012 \\
\hline & $\begin{array}{l}\text { Sunflower bee pollen from } \\
\text { Western Slovakia }\end{array}$ & $\begin{array}{l}691.67 \pm 7.76-803.33 \pm 3.30 \\
\mathrm{mg} / \mathrm{kg}\end{array}$ & $\begin{array}{l}\text { Fatrcová-Šramková et } \text { al. } \\
2016\end{array}$ \\
\hline & Bee pollen from Korea & 7.4-20.4 $\mu \mathrm{g}$ GAE/mg extract & Kim et al. 2015 \\
\hline & Unifloral bee pollen from Turkey & $\begin{array}{l}2340.07 \pm 199.32 \mathrm{mg} \\
\mathrm{GAE} / 100 \mathrm{~g}\end{array}$ & Özkök and Silici 2017 \\
\hline & Bee pollen from Venezuela & $396.7-1286.7 \mathrm{GAE} / 100 \mathrm{~g}$ & Pérez-Pérez et al. 2012 \\
\hline & Bee pollen from Italy & $\begin{array}{l}4.2 \pm 0.4-29.6 \pm 0.9 \mathrm{mg} \mathrm{GAE} / \mathrm{g} \\
\text { DW }\end{array}$ & Rocchetti et al. 2019 \\
\hline & Bee pollen from Central Chile & $22.8-918.4 \mathrm{mg} / \mathrm{kg}$ & Velasquez et al. 2017 \\
\hline & $\begin{array}{l}\text { Multifloral fresh bee pollen from } \\
\text { Turkey }\end{array}$ & $14.42 \pm 0.60 \mathrm{mg} \mathrm{GAE} / \mathrm{g}$ & Kanar and Mazı 2019 \\
\hline & Bee pollen from Turkey & $\begin{array}{l}26.69 \pm 0.595-43.42 \pm 0.779 \\
\mathrm{mg} \mathrm{GAE} / \mathrm{g}\end{array}$ & Mayda et al. 2020 \\
\hline
\end{tabular}

Rutin (RE), gallic acid (GAE), quercetin (QE), free phenolic extracts (FPE), and bound phenolic extracts (BPE) 


\section{DERLEME / REVIEW}

Table 2. Antioxidant capacities of bee pollens and methods used to determine antioxidant capacity.

\begin{tabular}{|c|c|c|c|}
\hline Bee pollen origin & Method & Antioxidant capacity & Reference \\
\hline Monofloral bee pollen from & $\mathrm{DPPH}$ & $10.0 \pm 0.3-110.8 \pm 1.3 \mu \mathrm{mol} \mathrm{TE} / \mathrm{g}$ & \multirow{2}{*}{ De-Melo et al. 2018} \\
\hline Brazil & ORAC & $133.7 \pm 7.3-542.0 \pm 20.7 \mu \mathrm{mol} \mathrm{TE} / \mathrm{g}$ & \\
\hline $\begin{array}{l}\text { Bee pollen from Turkey and } \\
\text { Russia }\end{array}$ & DPPH & $60.35 \pm 0.03-81.41 \pm 0.0 \%$ & Özcan et al. 2019 \\
\hline $\begin{array}{l}\text { Multifloral fresh bee pollen } \\
\text { from Turkey }\end{array}$ & DPPH & $0.29 \pm 0.01 \mathrm{IC}_{50}(\mathrm{mg}$ dry pollen/ml) & Kanar and Mazı 2019 \\
\hline $\begin{array}{l}\text { Bee pollens from Europe } \\
\text { Countries }\end{array}$ & ORP & 16.27-39.40 mg RUE/10 g & $\begin{array}{l}\text { Adaškevičiūtè et al. } \\
2019\end{array}$ \\
\hline Bee pollen from Korea & DPPH & $13.0-50.1 \%$ & Kim et al. 2015 \\
\hline \multirow[t]{3}{*}{ Bee pollens from Italy } & ABTS & $49.9 \pm 6.2-216.3 \pm 4.6 \mu \mathrm{mol} \mathrm{TE} / \mathrm{g} \mathrm{DW}$ & \multirow{3}{*}{ Rocchetti et al. 2019} \\
\hline & DPPH & $11.9 \pm 6.4-134.7 \pm 4.3 \mu \mathrm{mol} \mathrm{TE} / \mathrm{g} \mathrm{DW}$ & \\
\hline & ORAC & $105.0 \pm 19.4-916.1 \pm 27.7 \mu \mathrm{molTE} / \mathrm{g}$ DW & \\
\hline \multirow[t]{2}{*}{ Tuscan bee pollen from Italy } & DPPH & $37.95 \pm 0.19-94.45 \pm 0.01 \%$ & \multirow{2}{*}{ Gabriele et al. 2015} \\
\hline & ORAC & $519.45 \pm 15.07-677.70 \pm 12.92 \mu \mathrm{mol} \mathrm{TE} / \mathrm{g}$ & \\
\hline \multirow[t]{2}{*}{ Bee pollen from Portugal } & DPPH & $2.0 \mathrm{mg} / \mathrm{mL}-4.3 \mathrm{mg} / \mathrm{mL}$ & \multirow{2}{*}{ Feás et al. 2012} \\
\hline & $\mathrm{BCB}$ & $3.1-5.9 \pm 0.9 \mathrm{mg} / \mathrm{mL}$ & \\
\hline $\begin{array}{l}\text { Sunflower bee pollen from } \\
\text { Western Slovakia }\end{array}$ & DPPH & $47.97 \pm 0.29-50.46 \pm 0.43 \%$ & $\begin{array}{l}\text { Fatrcová-Šramková et } \\
\text { al. } 2016\end{array}$ \\
\hline \multirow[t]{3}{*}{ Anzer pollen from Turkey } & FRAP & 11.77-105.06 $\mu \mathrm{mol}$ Trolox/g & \multirow{3}{*}{$\begin{array}{l}\text { Ulusoy and Kolayli } \\
2014\end{array}$} \\
\hline & CUPRAC & $33.1-86.8 \mathrm{mmol} / \mathrm{g}$ & \\
\hline & DPPH & $0.65-8.20 \mathrm{mg} / \mathrm{mL}$ & \\
\hline \multirow[t]{3}{*}{ Bee pollen from Poland } & TAA & $6.8-86.4 \%$ & \multirow{3}{*}{ Leja et al. 2007} \\
\hline & DPPH & $8.6-91.3 \%$ & \\
\hline & HRSA & $10.5-92.7 \%$ & \\
\hline \multirow[t]{2}{*}{ Bee pollen from Egypt } & DPPH & $15 \%$ & \multirow{2}{*}{ Mohdaly et al. 2015} \\
\hline & ABTS & $76.51 \%$ & \\
\hline \multirow[t]{3}{*}{ Bee pollen from Brazil } & ORAC & 228.02-411.39 mmol eq.Trolox /g pollen & \multirow{3}{*}{$\begin{array}{l}\text { Soares de Arruda et al. } \\
2020\end{array}$} \\
\hline & DPPH & 1.68-7.77 mg pollen/mL extract & \\
\hline & BCB & $72.38-90.27 \%$ & \\
\hline \multirow[t]{3}{*}{ Bee pollen from Turkey } & CUPRAC & $6.25-257.27 \mu \mathrm{mol} \mathrm{TE} / \mathrm{g}$ & \multirow{3}{*}{$\begin{array}{l}\text { Dulger Altiner et al. } \\
2020\end{array}$} \\
\hline & ABTS & $6.20-111.40 \mu \mathrm{mol} \mathrm{TE} / \mathrm{g}$ & \\
\hline & DPPH & $0.44-83.84 \mu \mathrm{mol} \mathrm{TE} / \mathrm{g}$ & \\
\hline $\begin{array}{l}\text { Bee pollen from Central } \\
\text { Chile }\end{array}$ & FRAP & $6.86-52.99 \mathrm{~g} \mathrm{GAE} / \mathrm{kg}$ & Velasquez et al. 2017 \\
\hline Bee pollen from Venezuela & TEAC & $\begin{array}{l}0.5-1.84 \mu \mathrm{moles} \text { Trolox equivalents } \\
\text { TEAC } / 100 \mathrm{~g}\end{array}$ & $\begin{array}{l}\text { Pérez-Pérez et al. } \\
2012\end{array}$ \\
\hline $\begin{array}{l}\text { Unifloral bee pollen samples } \\
\text { from Turkey }\end{array}$ & DPPH & $\begin{array}{l}42.37 \pm 3.81 \mathrm{mg} \mathrm{AAE} / \mathrm{g} \\
89.66 \pm 0.39 \%\end{array}$ & Özkök and Silici 2017 \\
\hline Bee pollen from Brazil & DPPH & $810-4690 \mu \mathrm{g} / \mathrm{mL}$ & Carpes et al. 2009 \\
\hline \multirow[t]{2}{*}{ Bee pollen from Turkey } & DPPH & $3.08 \pm 0.056-3.85 \pm 0.030 \mathrm{mg} \mathrm{TE} / \mathrm{g}$ & \multirow{2}{*}{ Mayda et al. 2020} \\
\hline & ABTS & $1.80 \pm 0.052-5.980 \pm 0.100 \mathrm{mg}$ TEAC/g & \\
\hline
\end{tabular}

ORP: oxidation-reduction potential, BCB: $\beta$-Carotene bleaching, DPPH: 2,2-diphenyl-1-picrylhydrazyl, ABTS: 2,2'-azinobis 3-ethylbenzothiazoline-6-sulfonic acid, ORAC: oxygen radical absorbance capacity, ORP: oxidation reduction potential, FRAP: ferric reducing ability of plasma, CUPRAC: cupric reducing antioxidant capacity, TEAC: trolox equal antioxidant capacity, TAA: total antioxidant activity, HRSA: hydroxyl radical-scavenging activity.

\section{Conclusion}

The previously mentioned studies seem to confirm the great potential of bee pollen as a natural agent capable of counteracting the damaging effects of oxidation. In recent years, the food industry has paid great attention to bee pollen due to its antioxidant compounds. Bee pollen may be an important candidate for developing many food supplements and pharmaceutical products due to its rich bioactive compounds. 
Conflict of interests: The authors declare that there is no conflict of interest regarding the publication of this paper.

\section{REFERENCES}

Adaškevičiūtè, V., Kaškonienè, V., Kaškonas, P., Barčauskaitè, K., Maruška. A. 2019. Comparison of physicochemical properties of bee pollen with other bee products. Biomolecules, $\quad$ 9(12): 819. doi.org/10.3390/biom9120819

Aguilar, TAF., Navarro, BCH., Perez, JAM. 2016. Endogenous antioxidants: a review of their role in oxidative stress. In: Morales-Gonzalez JA, Morales-González A, Madrigal-Santillan EO (editors). A master regulator of oxidative stress-the transcription factor nrf2. London, IntechOpen. pp. 4-19. ISBN: 978-953-512838-0 doi.org/10.5772/65715

Aličić, D., Šubarić, D., Jašić, M., Pašalić, H., Ačkar $Đ$. 2014. Antioxidant properties of pollen HRČAK, 3(1): 6-12.

Atsalakis, E., Chinou, I., Makropoulou, M., Karabournioti, S., Graikou, K. 2017. Evaluation of phenolic compounds in Cistus creticus bee pollen from Greece. Antioxidant and antimicrobial properties Nat. Prod. Commun, 12(11):1813-1816., doi.org/10.1177/1934578X1701201141

Birben, E., Sahiner, UM., Sackesen, C., Erzurum, S., Kalayci, O. 2012. Oxidative stress and antioxidant defense World Allergy Organ J, $5(1)$ :

9-19., doi.org/10.1097/WOX.0b013e3182439613

Campos, MG., Bogdanov, S., de Almeida-Muradian, LB., Szczesna, T., Mancebo, Y., Frigerio, C., Ferreira, F. 2008. Pollen composition and standardisation of analytical methods J. Apic. Res., $\quad 47(2)$ : 154-161. doi.org/10.1080/00218839.2008.11101443

Campos, MG., Webby, RF., Markham, KR., Mitchell, KA., Da Cunha, AP. 2003. Age-induced diminution of free radical scavenging capacity in bee pollens and the contribution of constituent flavonoids J. Agric. Food Chem, 51(3): 742-745., doi.org/10.1021/jf0206466.

Carpes, ST., Mourão, GB., De Alencar, SM., Masson, ML. 2009. Chemical composition and free radical scavenging activity of Apis mellifera bee pollen from Southern Brazil
Brazilian J. Food Technol, 12(03) 220-229., doi.org/10.4260/BJFT2009800900016

Cho, KJ., Seo, JM., Kim, JH. 2011. Bioactive lipoxygenase metabolites stimulation of NADPH oxidases and reactive oxygen species Mol Cells. 32(1): 1-5., doi.org/10.1007/s10059-011-1021-7

Cornara, L., Biagi, M., Xiao, J., Burlando, B. 2017. Therapeutic properties of bioactive compounds from different honeybee products Front Pharmacol. 8: 412. doi.org/10.3389/fphar.2017.00412

de Florio Almeida, J., dos Reis, AS., Heldt, LFS., Pereira, D., Bianchin, M., de Moura, C., PlataOviedo, MV., Haminiuk, CWI., Riberio, IS., Pinto da Luz, CF., Carpes, ST. 2017. Lyophilized bee pollen extract: A natural antioxidant source to prevent lipid oxidation in refrigerated sausages LBWTAP. 76(Part B): 299-305., doi.org/10.1016/j.Iwt.2016.06.017

De-Melo, AAM., Estevinho, LM., Moreira, MM., Delerue-Matos, C., Freitas, ADSD., Barth, OM., Almeida-Muradian, LBD. 2018. Phenolic profile by HPLC-MS, biological potential, and nutritional value of a promising food: Monofloral bee pollen J. Food Biochem 42(5), e12536., https://doi.org/10.1111/jfbc.12536

Denisow, B., Denisow-Pietrzyk, M. 2016. Biological and therapeutic properties of bee pollen: a review J Sci Food Agric. 96 (13):4303-4309., doi.org/10.1002/jsfa.7729

Dulger Altiner, D., Sandikci Altunatmaz, S., Sabuncu, M., Aksu, F., Sahan, Y. 2020. Invitro bioaccessibility of antioxidant properties of bee pollen in Turkey Food Sci (AHEAD). doi.org/10.1590/fst.10220

Fatiha, M., Abdelkader, T. 2019. Study of antioxidant activity of pyrimidinium betaines by DPPH radical scavenging method $J$ Anal Pharm Res. 8: doi.org/10.15406/japlr.2019.08.00308 33-36.,

Fatrcová-Šramková, K., Nôžková, J., Máriássyová, M., Kačániová, M. 2016. Biologically active antimicrobial and antioxidant substances in the Helianthus annuus L. bee pollen J Environ Sci Health B. Part B, 51(3):176-181., doi.org/10.1080/03601234.2015.1108811

Feás, X., Vázquez-Tato, MP., Estevinho, L., Seijas, JA., Iglesias, A. 2012. Organic bee pollen: botanical origin, nutritional value, bioactive compounds, antioxidant activity and 


\section{DERLEME / REVIEW}

microbiological quality Molecules. 17(7): 8359-8377., doi.org/10.3390/molecules17078359

Gabriele, M., Parri, E., Felicioli, A., Sagon, S., Pozzo, L., Biondi, C., Domenici, V., Pucci, L. 2015. Phytochemical composition and antioxidant activity of Tuscan bee pollen of different botanic origins Ital. J. Food Saf. 27(2):248-259., doi.org/10.14674/1120$1770 /$ ijfs.v191

Guiné, RPF. 2015. Bee Pollen: Chemical Composition and Potential Beneficial Effects on Health Curr Nutr Food Sci, 11(4):301-308., doi.org/10.2174/15734013116661506301816 15

Guo, C., Sun, L., Chen, X., Zhang, D. 2013. Oxidative stress, mitochondrial damage and neurodegenerative diseases Neural Regen Res. 8(21):2003-2014., doi.org/10.3969/j.issn.1673-

5374.2013.21.009

Harif Fadzilah, N., Jaapar, MF., Jajuli, R., Wan Omar, WA. 2017. Total phenolic content, total flavonoid and antioxidant activity of ethanolic bee pollen extracts from three species of Malaysian stingless bee J. Apic. Res. 56(2): 130-135. doi.org/10.1080/00218839.2017.1287996

He, L., He, T., Farrar, S., Ji, L., Liu, T., Ma, X. 2017. Antioxidants maintain cellular redox homeostasis by elimination of reactive oxygen species Cell Physiol Biochem, 44(2):532553., doi.org/10.1159/000485089

Kanar, Y., Mazı, BG. 2019. Effect of different drying methods on antioxidant characteristics of beepollen Meas. 13:3376-3386., doi.org/10.1007/s11694-019-00283-5

Karkar, B., Şahin, S., Güneş, ME. 2020. Evaluation of antioxidant properties and determination of phenolic and carotenoid profiles of chestnut bee pollen collected from Turkey J. Apic. Res. 1-10., doi.org/10.1080/00218839.2020.1844462

Kaškonienè, V., Ruočkuvienè, G., Kaškonas, P., Akuneca, I., Maruška, A. 2015. Chemometric analysis of bee pollen based on volatile and phenolic compound compositions and antioxidant properties Food Anal. Methods. 8(5):1150-1163., $\quad$ doi.org/10.1007/s12161014-9996-2
Kim, SB., Jo, YH., Liu, Q., Ahn, JH., Hong, IP., Han, SM., Hwang, BY., Lee, MK. 2015. Optimization of extraction condition of bee pollen using response surface methodology: correlation between anti-melanogenesis, antioxidant activity, and phenolic content Molecules. 20(11):19764-19774., doi.org/10.3390/molecules201119656

Kocot, J., Kiełczykowska, M., Luchowska-Kocot, D., Kurzepa, J., Musik, I. 2018. Antioxidant potential of propolis, bee pollen, and royal jelly: Possible medical application Oxid. 7074209., doi.org/10.1155/2018/7074209

Komosinska-Vassev, K., Olczyk, P., Kaźmierczak, J., Mencner, L., Olczyk, K. 2015. Bee pollen: chemical composition and therapeutic application J Evid Based Complementary Altern Med. 2015., doi.org/10.1155/2015/297425

Kuciel-Lewandowska, J., Kasperczak, M., Bogut, B., Heider, R., Laber, WT., Laber, W., PaprockaBorowicz, M. 2020. The Impact of Health Resort Treatment on the Nonenzymatic Endogenous Antioxidant System Oxid. 2020(147):1-9., doi.org/10.1155/2020/8423105

LeBlanc, BW., Davis, OK., Boue, S., DeLucca, A., Deeby, T. 2009. Antioxidant activity of Sonoran Desert bee pollen Food Chem. 115(4):1299-1305., doi.org/10.1016/j.foodchem.2009.01.055

Leja, M., Mareczek, A., Wyżgolik, G., KlepaczBaniak, J., Czekońska, K. 2007. Antioxidative properties of bee pollen in selected plant species Food Chem. 100(1):237-240., doi.org/10.1016/j.foodchem.2005.09.047

Lobo, V., Patil, A., Phatak, A., Chandra, N. 2010. Free radicals, antioxidants and functional foods: Impact on human health Pharmacogn Rev. 4(8): 118-126., doi.org/10.4103/09737847.70902

Masella, R., Di Benedetto, R., Varì, R., Filesi, C., Giovannini, C. 2005. Novel mechanisms of natural antioxidant compounds in biological systems: involvement of glutathione and glutathione-related enzymes J Nutr Biochem. 16(10): doi.org/10.1016/j.jnutbio.2005.05.013

Mărghitaschedilla, LA., Stanciu, OG., Dezmirean, DS., Bobiscedilla, O., Popescu, O., Bogdanov, S., Campos, MG. 2009. In vitro 
antioxidant capacity of honeybee-collected pollen of selected floral origin harvested from Romania. Food Chem. 115(3):878-883., doi.org/10.1016/j.foodchem.2009.01.014

Mayda, N., Özkök, A., Bayram, NE., Gerçek, YC., Sorkun, K. 2020. Bee bread and bee pollen of different plant sources: determination of phenolic content, antioxidant activity, fatty acid and element profiles Meas. 14(4): 7951809., doi.org/10.1007/s11694-020-00427-y.

Mohdaly, AA., Mahmoud, AA., Roby, MH., Smetanska, I., Ramadan, MF. 2015. Phenolic extract from propolis and bee pollen: composition, antioxidant and antibacterial activities J. Food Biochem. 39(4): 538-547., doi.org/10.1111/jfbc. 12160.

Moniruzzaman, M., Khalil, MI., Sulaiman, SA., Gan, SH. 2011. Advances in the analytical methods for determining the antioxidant properties of honey: a review Afr J Tradit Complement Altern $\quad$ Med. 9(1): 36-42., doi.org/10.4314/ajtcam.v9i1.5.

Okan, OT., Varlibaş, H., Öz, M., Deniz, İ. 2013. Antioksidan analiz yöntemleri ve doğu karadeniz bölgesinde antioksidan kaynağı olarak kullanılabilecek odun dışı bazı bitkisel ürünler Kastamonu Üniv. Orman Fak. Derg. 13(1): 48-59.

Olczyk, P., Koprowski, R., Kaźmierczak, J., Mencner, L., Wojtyczka, R., Stojko, J, Olczyk, K., Komosinska-Vassev, K. 2016. Bee pollen as a promising agent in the burn wounds treatment Evid Based Complement Alternat Med. $\quad 2016$ : 8473937. doi.org/10.1155/2016/8473937

Oliveira, KC., Moriya, M., Azedo, RA., AlmeidaMuradian, LBD., Teixeira, EW., Alves, ML., Moreti, AC. 2009. Relationship between botanical origin and antioxidants vitamins of bee-collected pollen Química Nova, 32(5):1099-1102., doi.org/10.1590/S010040422009000500003

Oliveira, RGD., Jain, S., Freitas, LDS., Araújo, EDD. 2019. Phenolic compound, nutritional and antioxidant profile of pollen collected by the genus melipona in North Eastern Brazil Brazilian J. Food Technol. 22(4)., doi.org/10.1590/1981-6723.07918

Özcan, MM., Aljuhaimi, F., Babiker, EE., Uslu, N., Ceylan, DA., Ghafoor, K., Özcan, MM., Dursun, N., Ahmed, IM., Fadimu, GJ.,
Alsawmahi, ON. 2019. Determination of antioxidant activity, phenolic compound, mineral contents and fatty acid compositions of bee pollen grains collected from different locations J. Apic. Res. 63(1): 69-79., doi.org/10.2478/jas-2019-0004

Özkök, D., Silici, S. 2017. Antioxidant activities of honeybee products and their mixtures. Food Sci Biotechnol. 26(1): 201-206., doi.org/10.1007/s10068-017-0027-0

Panche, AN., Diwan, AD., Chandra, SR. 2016. Flavonoids: an overview J Nutr Sci. 5: 1-5., doi.org/10.1017/jns.2016.41.

Pascoal, A., Rodrigues, S., Teixeira, A., Feás, Estevinh, LM. 2014. Biological activities of commercial bee pollens: Antimicrobial, antimutagenic, antioxidant and antiinflammatory Food Chem Toxicol. 63: 233239., doi.org/10.1016/j.fct.2013.11.010.

Pérez-Pérez, EM., Vit, P., Rivas, E., Sciortino, R., Sosa, A., Tejada, D., Rodríguez-Malaver, AJ. 2012. Antioxidant activity of four color fractions of bee pollen from Mérida, Venezuela Arch Latinoam Nutr. 62: 375-80., PMID: 24020258.

Pham-Huy, LA., He, H., Pham-Huy, C. 2008. Free radicals, antioxidants in disease and health Int J Biomed Sci. 4: 89-96., PMID: 23675073

Phaniendra, A., Jestadi, DB., Periyasamy L. 2015. Free radicals: properties, sources, targets, and their implication in various diseases Indian J Clin Biochem. 30(1):11-26., doi.org/10.1007/s12291-014-0446-0

Pisoschi, AM., Negulescu, GP. 2011. Methods for total antioxidant activity determination: a review Biochem. Analytical Biochemistry. $1(1): 106$. doi.org/10.4172/21611009.1000106

Pizzino, G., Irrera, N., Cucinotta, M., Pallio, G., Mannino, F., Arcoraci, V., Squadrito, F., Altavilla, D., Bitto, A. 2017. Oxidative Stress: Harms and Benefits for Human Health Oxid Med Cell Longev. 2017, 8416763., doi.org/10.1155/2017/8416763

Rao, PS., Kalva, S., Yerramilli, A., Mamid, S. 2011. Free radicals and tissue damage: Role of antioxidants Free Radic Biol Med. 1(4): 2-7., doi.org/10.4103/0973-7847.70902

Rocchetti, G., Castiglioni, S., Maldarizzi, G., Carloni, P., Lucini, L. 2019. UHPLC-ESI-QTOF-MS 


\section{DERLEME / REVIEW}

phenolic profiling and antioxidant capacity of bee pollen from different botanical origin $\mathrm{J}$. Food Sci. Technol. 54: 335-346., doi.org/10.1111/ijfs.13941

Romero, AC., Hernández, EGO., Cerón, TF., Chávez, AÁ. 2013. The exogenous antioxidants. Ed.: Jose Antonio MoralesGonzalez. Oxidative Stress and Chronic Degenerative Diseases-A Role for Antioxidants, IntechOpen, London, UK. 33. doi.org/10.5772/52490

Saral, Ö., Kilicarslan, M., Şahin, H., Yildiz, O., Dincer, B. 2019. Evaluation of antioxidant activity of bee products of different bee races in Turkey. Turk J Vet Anim Sci. 43(4): 441447., doi.org/10.3906/vet-1901-3

Šarić, A., Balog, T., Sobočanec, S., Kušić, B., Šverko, V., Rusak, G., Likić, S., Bubalo, D., Pinto, B., Reali, D., Marotti, T. 2009. Antioxidant effects of flavonoid from Croatian Cystus incanus L. rich bee pollen. Food Chem Toxicol. 47(3): 547-554., doi.org/10.1016/j.fct.2008.12.007

Sharma, P., Jha, AB., Dubey, RS., Pessarakli, M. 2012. Reactive oxygen species, oxidative damage, and antioxidative defense mechanism in plants under stressful conditions Turk J Bot. 2012., doi.org/10.1155/2012/217037

Soares de Arruda, VA., Vieria dos Santos, A., Figueiredo Sampaio, D., da Silva Araújo, E., de Castro Peixoto, AL., Estevinho, LM., de Almeida-Muradian, LB. 2020. Brazilian bee pollen: phenolic content, antioxidant properties and antimicrobial activity J. Apic. Res. 1 1-9., doi.org//10.1080/00218839.2020.1840854

Sun, L., Guo, Y., Zhang, Y., Zhuang, Y. 2017. Antioxidant and anti-tyrosinase activities of phenolic extracts from rape bee pollen and inhibitory melanogenesis by cAMP/MITF/TYR pathway in B16 mouse melanoma cells Front Pharmacol. doi.org/10.3389/fphar.2017.00104

Thakur, M., Nanda, V. 2020. Composition and functionality of bee pollen: A review Trends Food Sci Technol. 98: 82-106., doi.org/10.1016/j.tifs.2020.02.001

Ulusoy, E., Kolayli, S. 2014. Phenolic composition and antioxidant properties of Anzer bee pollen J. Food Biochem. 38(1): 73-82., doi.org/10.1111/jfbc. 12027

Velasquez, P., Rodriguez, K., Retamal, M., Giordano, A., Valenzuela, LM., Montenegro, G. 2017. Relation between composition, antioxidant and antibacterial activities and botanical origin of multi-floral bee pollen $J$. Appl. Bot. Food Qual. 90(1): 306-314., doi.org/10.5073/JABFQ.2017.090.038

Villanueva, MO., Marquina, AD., Serrano, RB., Abellán, GB. 2002. The importance of beecollected pollen in the diet: a study of its composition Int J Food Sci Nutr. 53(3): 217224., doi.org/10.1080/09637480220132832.

Warraich, YA., Hussain, F., Kayani, HUR. 2020. Aging-Oxidative stress, antioxidants and computational modeling Heliyon. 6(5): E04107., doi.org/10.1016/j.heliyon.2020.e04107

Yang, Y., Zhang, JL., Zhou, Q., Wang, L., Huang, W., Wang, RD. 2019. Effect of ultrasonic and ball-milling treatment on cell wall, nutrients, and antioxidant capacity of rose (Rosa rugosa) bee pollen, and identification of bioactive components $J$ Sci Food Agric. 99(12): $\quad$ 5350-5357., doi.org/10.1002/jsfa.9774. 